\title{
A abertura da Escola Paulista de Medicina
}

\author{
The inauguration of the \\ Escola Paulista de Medicina
}

\author{
Lilian Koifman \\ Professora do Departamento de Planejamento em Saúde do \\ Instituto de Saúde da Comunidade/UFF \\ Rua Marquês do Paraná, 303 Prédio Anexo - HUAP — 3o andar \\ 24030-210 Niterói — RJ Brasil \\ lilian@vm.uff.br
}

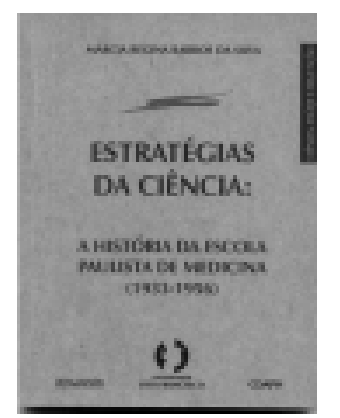

Márcia Regina Barros da Silva

Estratégias da ciência: a bistória da Escola Paulista de Medicina (1933-1956) Bragança Paulista, Edusf, 2003, 230p.
$E$ stratégias da ciência: a história da Escola Paulista de Medicina (1933-1956) é um estudo histórico que traz grande contribuição para a compreensão do processo de institucionalização do ensino da medicina no estado de São Paulo, na primeira metade do século XX. Foi originalmente apresentado como dissertação de mestrado defen-dida pela historiadora no Programa de História Social da Universidade de São Paulo, em 1988.

A autora faz seu relato concentrando-se nos fatos relacionados à abertura da Escola Paulista de Medicina entre os anos 1933 e 1956, permeando esses fatos e os nomes dos profissionais envolvidos com os acontecimentos referentes ao ensino médico, ensino superior e reformas de ensino propostas no período.

O fundamento do trabalho de pesquisa sobre o qual se baseia a obra, segundo a própria autora, é a visão de que inexiste uma ciência independente do campo sociocultural no qual ela se insere, tanto em suas atividades cotidianas quanto nos métodos e práticas utilizadas e, ainda, nos conhecimentos transmitidos. A atividade científica "constitui e ao mesmo tempo é constituída pela sociedade na qual se insere" (p. 11).

$\mathrm{Na}$ linha do que propõem autores como Bruno Latour e outros, Márcia Regina Barros da Silva avalia que somente pelo entendimento das práticas que compõem o conhecimento científico e do seu valor como trajetória torna-se possível perceber a historicidade daquilo que se costuma entender por ciência.

Embora reconhecendo o descompasso com relação a diversos trabalhos de pesquisa realizados no Brasil, considera necessário reafirmar que a história institucional significa um aspecto importante e que possibilita entender as implicações da idéia de que as ciências estão inseridas e só podem ser lidas em sociedades historicamente determinadas.

Nesse sentido, o livro de Márcia Regina avalia os processos de criação de uma instituição de ensino superior - a Escola Paulista de Medicina -, as relações entre os principais agentes responsáveis pela sua criação e os processos utilizados para legitimar a instituição. Tais processos tanto procuravam dotar a instituição de competência e autoridade científica, quanto tinham o intuito de formar profissionais que fossem 
reconhecidamente competentes para lidar com a doença e a saúde, além de produzir conhecimentos a partir delas.

Como nos conta a historiadora, o estudo da criação de uma instituição de ensino superior no início dos anos 1930 - inicialmente particular e transformada em estabelecimento público em meados dos anos 1950 - propicia a reflexão sobre as especificidades da educação médica realizada em São Paulo naquele período. Isso também remete à discussão sobre as bases em que se deu a caracterização do médico formado nesse contexto, na condição de intelectual, profissional e cientista desempenhando um papel específico na sociedade paulista da época.

A abordagem da autora descreve uma instituição cuja trajetória e cujo desenvolvimento foram sendo estabelecidos com base em propo-sições coerentes com o período pós-1920, apontado como momento de discussão e redefinição da posição e função dos intelectuais na composição de uma nova nação brasileira.

Márcia Regina relata com riqueza de detalhes o caso da Escola Paulista de Medicina. Relaciona o encaminhamento de suas estratégias de institucionalização com um ideário baseado no saber especializado e na competência científica como suportes para o desenvolvimento social. Isso especificamente no caso da sociedade paulista, que, naquele momento, ampliava o debate em torno da fundação de uma universidade no estado e aprofundava questões relacionadas com a industrialização do país.

O livro descreve os médicos que participaram da criação da Escola Paulista de Medicina como representantes de uma elite científica nacional, professores das principais escolas médicas do país (faculdades de medicina de São Paulo, Rio de Janeiro e Bahia). Apesar de atuarem em diferentes campos de conhecimento, eles fizeram parte de um processo que pretendia contribuir para o reordenamento da sociedade, considerando a educação, o conhecimento científico e o saber organizado em bases nacionais fatores de ordem e união nacional. "O objetivo imediato dessa visão foi o de atrelar ciência a bem-estar social" (p. 15). Tal argumento foi utilizado pelos fundadores para o convencimento a respeito da importância da abertura da nova escola e seu hospital de clínicas. Eles afirmavam que essas duas vertentes eram necessárias para o bom funcionamento do sistema educacional e dos serviços de saúde de São Paulo.

A Escola Paulista de Medicina, segundo nos relata a historiadora, foi criada por esse grupo de médicos interessados em ampliar e descentralizar o ensino da medicina no estado a partir de 1933. Como, naquele momento específico estavam em movimento diferentes processos de reordenamento cultural, econômico e político, ganharam destaque as discussões sobre a ampliação de instituições dirigidas a diferentes ramos da formação profissional - na perspectiva de atender a um crescente desenvolvimento urbano e industrial como forma de ampliar a participação do ensino e da universidade na vida social do país.

Por isso o interesse de Márcia Regina Barros da Silva em relatar a constituição da Escola Paulista de Medicina como parte integrante dos processos de adequação institucional e administrativa que estavam sendo impostos ao sistema de ensino superior no Brasil. O estudo 
desse caso é de interesse, ainda, para entender as bases de sustentação da iniciativa de criação de uma instituição de ensino médico naquele momento.

A autora divide a trajetória da instituição em duas fases: uma entre a instalação do curso médico, em 1933, e o início da construção do hospital de clínicas; a outra vai da formatura da primeira turma, em 1938, até a federalização da escola, em 1956.

No primeiro capítulo, o objetivo maior da autora é discutir o processo de organização da própria idéia de se criar uma nova instituição de ensino médico em São Paulo, relacionando-a ao que estava acontecendo no ensino superior no Brasil e em especial no ensino médico paulista. O trabalho relata como dois projetos independentes se uniram para justificar a abertura da nova escola médica: por um lado, a insuficiência de vagas no ensino superior de medicina - ressaltada na imprensa paulista a partir da discussão de excedentes de alunos que, embora aprovados no vestibular, não obtinham vagas para ingressar na única escola de medicina do estado, a Faculdade de Medicina de São Paulo. Por outro, havia um grande número de professores descontentes com a dificuldade de ascensão ao cargo vitalício de professor catedrático, cujas vagas estavam todas preenchidas. Assim, somente a abertura de uma nova escola médica poderia ampliar as possibilidades de os professores ingressarem na carreira acadêmica.

Ao longo desse primeiro capítulo, Márcia Regina relata a montagem de um quebra-cabeças de desejos individuais dos participantes do grupo inicial de professores. Conjugando diversos interesses, eles acabariam integrando suas crenças e aspirações no discurso da fundação da nova escola médica, transformando o que era particular em ambição comum.

O segundo capítulo discute a criação da instituição a partir de dois aspectos: primeiro, o entendimento de sua organização acadêmica e científica, incluindo a constituição do hospital-escola; segundo, a caracterização das relações estabelecidas entre a nova escola e diferentes representantes da sociedade interessados na organização do ensino e da assistência médica hospitalar. Tem lugar aí também a descrição dos aspectos formais da instalação do curso médico, a organização do ensino e a implantação das cadeiras clínicas, até a saída do primeiro diretor, momento que a autora descreve como de mudança do encaminhamento geral da organização. Entre idas e vindas de inspetores do Ministério de Educação e da Saúde Pública para avaliar e reconhecer oficialmente a escola, são descritos os jogos de interesses entre os representantes do ensino médico da época e a nova escola - e como tais relações se refletiram a favor da instituição em vários momentos.

Foi interessante perceber o importante papel do governo federal na consolidação do projeto de criação da Escola Paulista de Medicina. Isso ratifica a hipótese proposta pela autora: além dos professores da instituição, ela foi criada e desenvolvida com a participação de diversos setores da sociedade, tendo recebido tanto o apoio financeiro como o necessário apoio político.

O período marcado pela segunda diretoria é relatado no terceiro capítulo, no qual percebe-se que o discurso que explicava as funções da escola passou a ressaltar cada vez mais o sentido científico, em detrimento das diretrizes definidas pela diretoria anterior, centradas nas funções sociais. As questões inicialmente colocadas como justificativa da abertura da instituição estavam ligadas aos problemas locais de ordem social e assistencial (evasão 
de estudantes do estado de São Paulo por falta de vagas e importância da assistência ao trabalhador, mão-de-obra necessária à economia paulista). No segundo momento, as atividades passaram a centrar-se no desenvolvimento da cultura, da ciência, no acúmulo de conhecimentos, no cultivo do amor à pátria e na consolidação do progresso do país. A partir dessa nova etapa foram abertos dois novos cursos: enfermagem e auxiliar técnico de laboratório. Começaram também a ser realizados concursos para lentes, o que não ocorrera na etapa anterior, quando os professores tinham sido convidados. Ampliaram-se igualmente as atividades de pesquisa.

Durante o governo do presidente Juscelino Kubitschek, após um longo processo de negociações, a Escola Paulista de Medicina tornouse uma instituição de ensino superior pública federal, em 1956. O hospital de clínicas, chamado Hospital São Paulo, continuou dirigido pela Sociedade para o Desenvolvimento da Medicina, como entidade particular e sem fins lucrativos.

Um registro muito relevante que Estratégias da ciência faz é a descrição de um momento histórico específico na criação dos hospitais-escolas, no que representou o auge da implantação do modelo 'hospitalcêntrico' no país. Destacava-se a grande importância atribuída à relação entre escola e hospital, valorizando-se o ensino prático realizado em instalações concebidas e construídas especificamente para esse fim, e não nos espaços de práticas existentes no conjunto 'real' de serviços. Naquele momento, a idéia predominante na Europa e nos Estados Unidos, a partir das influências do Relatório Flexner (1910), era de que o serviço comum não proporcionaria a melhor experiência para o aluno, uma vez que ali ele não teria preparado um ambiente didático entendido como ideal para suas atividades.

$\mathrm{Na}$ atualidade, as principais correntes do ensino médico brasileiro têm estimulado cenários de ensino-aprendizagem diversificados. As recomendações oficiais, descritas nas Diretrizes Curriculares Nacionais (2001), determinam que os cursos de medicina no Brasil (e outros cursos de saúde) devem propiciar aos estudantes a diversificação de cenários de ensino e aprendizagem. Isso inclui necessariamente os diferentes tipos de serviços de saúde, nos quais o profissional médico em formação participará da realidade de saúde do país. O mesmo espaço deve compreender ambientes para que os alunos discutam com professores, colegas, profissionais e comunidades as questões relativas à saúde e à doença, sem que se criem espaços artificialmente preparados para a aprendizagem.

O livro de Márcia Regina, contendo um registro histórico da abertura de uma nova escola médica paulista, nos instiga a fazer uma comparação com a atualidade. A abertura de escolas médicas no Brasil passa no momento por questionamentos e reestruturações. O Conselho Nacional de Saúde, em 15 de julho 2003, recomendou a suspensão da abertura de novas escolas médicas por um período de 180 dias. A resolução do CNS, além de cessar a abertura de novos cursos, também criou uma comissão interministerial entre os Ministérios da Saúde e da Educação para a formulação, naquele prazo, de critérios conjuntos para a autorização de abertura dos novos cursos. A idéia é que a comissão faça um estudo que permita estabelecer e "projetar a necessidade de profissionais e de especialistas do país, de acordo com as características regionais, sociais, econômicas e epidemiológicas, e de 
acordo com as novas orientações para a organização da atenção, de modo a garantir acesso e atenção integral à saúde de todos os brasileiros". ${ }^{1}$

É interessante registrar que o estado de São Paulo concentra a maior parte de escolas médicas do país. Talvez o relato que se encontra em Estratégias da ciência seja o começo de uma história, mostrando que a abertura de novas instituições de ensino nem sempre esteve refletida por um plano geral de necessidades do país e/ou do estado. Antes se baliza por crenças e aspirações de grupos que foram constituindo um discurso em prol da fundação de novas escolas médicas, transformando o que era particular em ambição comum. A pesquisa histórica nos fornece dados preciosos para esta reflexão.

A leitura do livro de Márcia Regina flui bastante agradavelmente, tanto para iniciados quanto para leigos. Detalhes dos nomes de cada professor que passou pela Escola Paulista de Medicina e das disciplinas lecionadas em cada ano da recém-aberta instituição formam um precioso registro para pesquisadores da área e interessados na história da abertura de um estabelecimento de ensino no início do século XX.

O livro contribui também para nossa formação acadêmica em geral, significando um ganho tanto para especialistas da área de história e da história das ciências, quanto para os leitores interessados pelos temas de educação médica.

\footnotetext{
${ }^{1}$ Brasil Ministério da Saúde. Secretaria de Gestão do Trabalho e daEducação na Saúde. Departamento de Gestão da Educação na Saúde. 'Abertura de cursos de graduação na área da saúde'. Documento apresentado ao Conselho Nacional de Saúde, 2003.
} 